\title{
Analisis Morfologi Doa dalam al-Qur'an Surat al-Baqarah 186
}

\author{
Himatul Istiqomah \\ Universitas Negeri Malang \\ himastiq@gmail.com
}

\begin{abstract}
This study not only aims to discribe derivation of the word do' $a$, but also composition of do'a. For this purpose, researcher uses qualitative descriptive method with morphological analysis. The result shows that the word do'a in Surah al-Baqarah 186 is mentioned three times with derivation form: دعوة; gerund = praying, الداع; subject = prayer, dan past verb = prayed. In addition, there are two things in the composition of doa, namely istijabah (فليستجيبوا (لي = hard work and iman (وليؤمنوا بي) = confidence. So, whoever want to be responded by God, he must do both of those things. Indeed, since someone prayed to God, from that time God also began to respond to his do'a.
\end{abstract}

Keywords: Composition of do'a, morphology, al-Qur'an

\begin{abstract}
Abstrak
Penelitian ini tidak hanya bertujuan untuk menguraikan derivasi kata doa, tapi juga komposisi doa. Untuk itu, peneliti menggunakan metode deskriptif kualitatif dengan analisis morfologi. Hasilnya, yaitu kata doa dalam Surat al-Baqarah 186 disebutkan sebanyak tiga kali dalam bentuk derivasi: دعوة; mashdar = permohonan, دالع; isim fa'il = pemohon, dan دعا; fi'il madhi = memohon. Di samping itu, ada dua hal yang menjadi komposisi doa, yaitu istijabah (فليستجيبوالي) = kerja keras dan iman (وليؤمنوا بي) = yakin. Jadi, siapapun yang ingin direspon oleh Tuhan, dia harus melakukan kedua hal tersebut. Sesungguhnya, sejak seseorang berdoa kepada Tuhan, sejak saat itu pula Tuhan mulai merespon doanya.
\end{abstract}

Kata kunci: Komposisi do'a, morfologi, al-Qur'an

\section{Pendahuluan}

Kitab al-Qur'an diwahyukan dengan bahasa Arab. Agar siapapun termotivasi untuk mendayagunakan akalnya, guna memahami pesan-pesan 
Tuhan di dalamnya. Semua diksi dan struktur kalimat dalam al-Qur'an menampilkan keunikan dan keindahan. Bahkan, bangsa Arab sendiri pun mengakuinya dan sangat mengagumi keindahannya. Malah, mereka menjadikan al-Qur'an sebagai referensi keilmuan bahasa Arab baru di samping tradisi oral yang sudah membudaya.

Termasuk keindahan al-Qur'an, yaitu adanya reduplikasi (pengulangan) pada beberapa diksi dengan berbagai bentuk derivasinya. Reduplikasi merupakan bagian dari pembahasan dalam morfologi (Ilmu Sharf). Menurut Sayyid Quthb, reduplikasi atau tikrar ini berfungsi untuk memberikan penegasan, penjelasan, tantangan, atau stimulan bagi setiap pemerhati Al-Qur'an. ${ }^{1}$

Salah satu contoh diksi yang mengalami reduplikasi dalam al-Qur'an, yaitu kata doa. Doa berasal dari bahasa Arab دعاء, yaitu bentuk isim mashdar dari verba دعا- يدعو. Doa berarti permohonan, ajakan, undangan, sapaan. Selain itu, doa juga diartikan dengan harapan atau pujian kepada Tuhan. ${ }^{2}$

Menurut Ozdemir, doa secara etimologi bermakna merayu, mengundang, memelas, mengutarakan, dan meminta. Secara terminologi, doa bermakna mendekatkan diri kepada Tuhan dengan sepenuh jiwa-raga untuk mengutarakan suatu permohonan. Adapun secara leksikal, doa bermakna menyeru kepada Tuhan dan memohon bantuan-Nya, agar terhindar dari mafsadat dan memperoleh manfaat. ${ }^{3}$ Doa dalam pandangan Ibnu Arabi merupakan bentuk komunikasi dengan Tuhan sebagai upaya untuk membersihkan diri dari indikasi kemusyrikan. ${ }^{4}$

Solehudin berpendapat bahwa doa memiliki beberapa tendensi makna. Doa sebagai permintaan, seperti dalam al-Qur'an surat Ghafir ayat 60. Doa sebagai panggilan, seperti dalam al-Qur'an surat al-Isra' ayat 52. Doa sebagai pujian, seperti dalam al-Qur'an surat al-Isra' ayat 11. Doa sebagai permohonan, seperti dalam al-Qur'an surat al-A'raf ayat 55 dan al-Baqarah $186 .{ }^{5}$

Banyak ayat al-Qur'an yang menyebutkan kata doa dengan berbagai bentuk derivasinya. Namun, fokus dalam kajian ini yaitu kata doa yang berarti permohonan, dalam al-Qur'an Surat al-Baqarah ayat 186. Kajian ini bertujuan untuk menguraikan derivasi kata doa dan komposisi doa yang terdapat dalam

${ }^{1}$ Fauzi Fathur Rosi, “Dimensi I'jaz Al-Qur'an pada Pengulangan Ayat dalam Surah ArRahman (Telaah Terhadap Tafsir Fi Dhilal Al-Qur'an Karya Sayyid Quthb)" (Tesis, UIN Sunan Ampel, 2018).

${ }^{2}$ Ebta Setiawan, “KBBI Online," Kamus Besar Bahasa Indonesia (KBBI) (blog), 2019, https://kbbi.web.id.

3 Awaludin Hakim, "Doa dalam Perspektif Al-Qur'an Kajian Tafsir Ibnu Kathir dan Tafsir Al-Azhar," Jurnal al-Fath, 1, 11 (2017): 45-70, hlm. 50-51.

${ }^{4}$ Dadang Ahmad Fajar, EpistimologiDoa (Bandung: NuansaCendekia, 2011), hlm. 53.

${ }^{5}$ Solehudin, "EpistimologiDoa KH AsepMukarram," Syifa Al-Qulub, 1, 2 (2017): 12 25, hlm. 16-17. 
ayat tersebut. Sehingga, ini akan memberikan penjelasan mengenai hakikat doa dan cara berdoa yang berkualitas.

Untuk merealisasikan tujuan itu, peneliti melakukan kajiandeskriptif kualitatif, di mana ruang lingkupnya tidak terlalu luas tapi justru dapat menghasilkan pemahaman yang mendalam ${ }^{6}$ dengan sajian deskripsi yang diteliti secara kritis.

Objek dalam penelitian ini yaituayat 186 dalam Al-Qur'an Surat AlBaqarah. Data dalam penelitian ini dikumpulkan dengan teknik simak catat, observasi, dan dokumentasi. Adapun teknik analisinya menggunakan analisis morfologi yang bersumber dari Al-Amtsilah At-Tashrifiyah karya KH. Ma'shum bin Ali, dengan tahapan: mencatat, mengurutkan, mengelompokkan, mengidentifikasi, kemudian mendeskripsikan data.

Penelitian sederhana dengan judul Analisis Morfologi Doa dalam Al-Qur'an Surat al-Baqarah Ayat 186 ini adalah kajian tematik al-Qur'an, yang merupakan lanjutan dari artikel edisi Konsep Manusia Sebagai Insan dalam Sebagian Ayat alQur'an,' yang diseminarkan dalam Konferensi Nasional Bahasa Arab IV di Universitas Negeri Malang, pada Oktober 2018.

Ini diharapkan dapat menjadi pemicu para peneliti lain, agar lebih tertarik untuk mengkaji al-Qur'an. Bagaimanapun, al-Qur'an merupakan pedoman dasar hidup yang diwahyukan Tuhan untuk menunjuki makhluk-Nya yang tersebar di semesta alam. Sehingga, mengkaji al-Qur'an tidak lain berarti membuat celah untuk mencahayai jalan hidup.

\section{Hasil dan Pembahasan}

\section{Morfologi}

Menurut Ramlan, morfologi adalah bagian dari ilmu bahasa yang mempelajari seluk-beluk struktur kata dan pengaruh perubahannya terhadap golongan dan arti kata. ${ }^{10}$ Dalam linguistik Arab, morfologi disebut dengan Ilmu Sharf atau Ilmu Mufradat, ilmu perbendaharaan kata. Yaitu, dalil-dalil tentang keadaan kata sebelum tersusun ke dalam suatu kalimat, atau ilmu yang

${ }^{6}$ Mahsun, Metode Penelitian Bahasa (Jakarta: Rajawali Press, 2014), hlm. 34.

${ }^{7}$ Ma'shum bin Ali, Al-Amtsilah At-Tashrifiyah (Maktabah Syekh Salim bin S'ad Nabhan, 1965).

${ }^{8}$ Lexy J Moleong, Metode Penelitian Kualitatif (Bandung: Remaja Rosdaya, 2004), hlm. 103.

${ }^{9}$ Himatul Istiqomah, "KonsepManusia Sebagai Insan dalam Sebagian Ayat Al-Qur’an," Prosiding Konasbara IV (2018): 439-45.

${ }^{10}$ M Ramlan, Ilmu Bahasa Indonesia, Morfologi. SuatuTinjauanDeskriptif (Yogyakarta, 1978), hlm. 1-2. 
membahas bentuk-bentuk kata dan aspeknya dalam bahasa Arab sebelum menjadi sebuah kalimat. ${ }^{11}$

Adapun proses morfologis yaitu serangkaian prosedur yang mengubah leksem atau satuan terkecil dari leksikon menjadi sebuah morfem ataupun kata. ${ }^{12}$ Artinya, dibutuhkan tiga unsur penting untuk membentuk sebuah morfem ataupun kata. Jika dinotasikan, ketiganya akan tampak seperti berikut.

\section{Leksem $\rightarrow$ Proses morfologis $\rightarrow$ Morfem/Kata}

Salah satu referensi yang masyhur perihal pembahasan Ilmu Sharf adalah Al-Amtsilab At-Tashrifizah karya KH. Ma'shum bin Ali. Dalam kitab ini, Ma'shum menyajikan pembahasan singkat tentang beberapa kaidah dalam morfologi Arab beserta contoh-contohnyadalam tabel sederhana. Khususnya kaidah afiksasi, baik berupa prefiks, infiks, konfiks, maupun sufiks.

Secara garis besar, ada dua istilah dasar yang digunakan dalam buku tersebut, yaitu wazan dan mawzun. Secara bahasa, wazan berasal dari kata waznun yang artinya timbangan. Wazan berfungsi sebagai pengukur kata-kata lain yang serupa dengan huruf dasar $f a$ ', 'ain, dan lam. ${ }^{13}$ Setiap huruf yang menempati posisi huruf $f a$ ' disebut dengan $f a$ ' fi'il.Setiap huruf yang menempati posisi huruf 'ain disebut dengan 'ain fïil.Setiap huruf yang menempati posisi huruf lam disebut dengan lam fi ill. Dengan demikian, wazan adalah pola dasar yang menjadi acuan bentuk kata dalam bahasa Arab. Sedangkan mawzun adalah semua kata yang mengacu pada wazan. Setiap wazan memiliki mawrun-nya sendiri, begitu pun sebaliknya.

\begin{tabular}{|c|c|c|}
\hline Leksem & Proses morfologis & Morfem/Kata \\
\hline Da'aa (دعا) & $\begin{array}{l}\text { Prefiks } Y a a^{\prime} \text { (ي dengan mengikuti wazan } \\
\text { yafulu (يفحل) }\end{array}$ & Yad'un (يدعو) \\
\hline & $\operatorname{Ain}(\varepsilon)$ & \\
\hline
\end{tabular}

Meski demikian, ada mawzun yang tidak sama persis dengan wazannya. Pengecualian ini biasanya berlaku pada mawzun-mawun yang sebagian huruf penyusun katanya tidak berupa huruf shabih(huruf Hijaiyah selain Alif, Wawn, dan $Y a$ ), tapi huruf 'ilab(Alif, Wawu, dan $Y a$ ). Ini juga berlaku pada isim mashdar, yaitu kata yang berfungsi sebagai mashdar tapi bentuknya tidak mengikuti aturan wazan-wazan mashdar.

\footnotetext{
${ }^{11}$ Retno Purnama Irawati, Linguistik Umum (Jakarta: Rineka Cipta, 2013), hlm. 101.

${ }^{12}$ Hanif Fathoni, "Pembentukan Kata dalam Bahasa Arab (Sebuah Analisis Morfologis 'K-T-B')," Jurnal At-Ta'dib, 1, 8 (2013): 45-48, hlm. 46.

13 Undang Syaripudin, "Pembuatan Game Ilmu Shorof (Tashrief) Sebagai Media Pembelajaran Bahasa Arab," Jurnal ISTEK, 1-2, 6 (2012): 125-36, hlm. 133.
} 


\begin{tabular}{|c|l|c|}
\hline Leksem & \multicolumn{3}{|c|}{ Proses morfologis } & Morfem/Kata \\
\hline Da'aa (دعاء) (دعاء) & $\begin{array}{l}\text { Sufiks Hamzah } \\
\text { mengikuti wazan dasar, fa'lan } \\
(\text { ) (فعل) }\end{array}$ & Du'aaan \\
\hline
\end{tabular}

\section{Derivasi Kata Doa pada Ayat 186 dalam al-Qur'an Surat al-Baqarah}

Menurut Keraf, derivasi diartikan sebagai suatu proses pengubahan identitas leksikal sebuah kata, dengan atau tanpa pemindahan kelas kata. ${ }^{14}$ Chaer berpendapat bahwa derivasi adalah pembentukan kata baru yang mana identitas leksikalnya berbeda dari kata dasarnya. ${ }^{15}$

Dalam bahasa Arab, derivasi lebih dikhususkan sebagai metode pembentukn kata baru yang berkaitan dengan konsep: nomina deverba (pembentukan nomina yang berasal dari verba), verba denomina (pembentukan verba yang berasal dari nomina), verba deajektiva (pembentukan verba yang berasal dari ajektiva). Wujud derivasi yaitu afiksasi dan modifikasi internal. ${ }^{16}$ Afiksasi bisa berupa prefiks (awalan), infiks (sisipan), sufiks (akhiran), ataupun konfiks (awalan dan akhiran). ${ }^{17}$

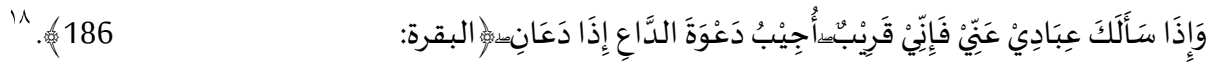

Apabila hamba-hamba-Ku bertanya kepadamu tentang Aku, sesunggubnya Aku berada dekat. Aku merespon permohonan seorang pemohon apabila dia memohon kepada-Ku QS. al-Baqarah: 186.

Pada ayat di atas, kata doa disebutkan sebanyak tiga kali dalam bentuk derivasi, yaitu: دعال dan , الداعة,

1. Da'watun (دعوة)

Artinya adalah permohonan. Ini adalah bentuk mashdar, yaitu verba yang dijadikan nomina. Dalam al-Amtsilah at-Tashrifiyah, ini termasuk dalam pembahasan Tashrif Istilabi yang ada pada bagian pertama dari Fïil Tsulatsi Mujarrad, yang mengikuti kaidah fa'ala-yaf'ulu-fa'lan.

14 Gorys Keraf, LinguistikBandinganHistoris (Jakarta: PT GramediaPustkaUtama, 1991), hlm. 158.

15 Abdul Chaer, LinguistikUmum (Jakarta: RinekaCipta, 2007), hlm. 175.

16 Tajudin Nur, "Infleksi Dan Derivasi Dalam Bahasa Arab: Analisis Morfologi," Metalingua, 2, 16 (2018): 273-83, hlm. 282.

${ }^{17}$ Arman Mappiase, “Afiks Derivasional Dan Infleksional Bahasa Sobey Di Kabupaten Sarmi Provinsi, Papua," Metalingua, 1, 15 (2017): 13-24, hlm. 23. https://tafsirq.com.

Wisnu Manupraba, "TafsirQ.com," Tafsir Al-Quran Online (blog), 2019, 


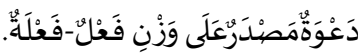

2. Ad-daäi (الداع)

Artinya adalah seorang pemohon. Ini adalah bentuk isim fa'il, yaitu subjek. Dalam al-Amtsilah at-Tashrifizah, ini termasuk dalam pembahasan Tasbrif Istilabi yang ada pada bagian pertama dari Fïil Tsulatsi Mujarrad.

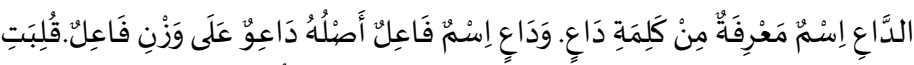

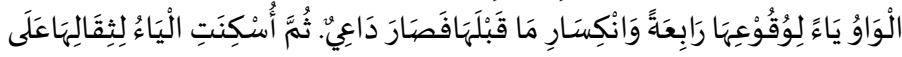

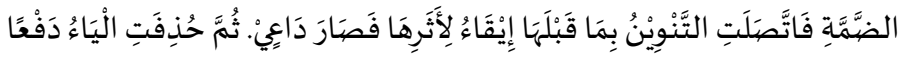

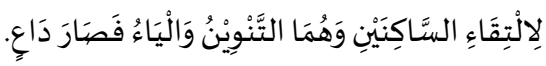

3. Da'aa (دعا)

Artinya adalah memohon. Ini adalah bentuk fi'il madhi, yaitu verba lampau. Dalam al-Amtsilah at-Tashrifiyah, ini termasuk dalam pembahasan Tashrif Istilahi yang ada pada bagian pertama dari Fïil Tsulatsi Mujarrad.

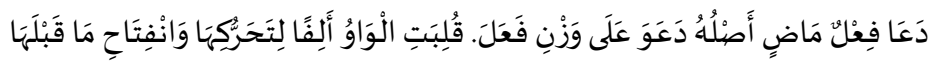

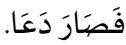

\section{Komposisi Doa pada Ayat 186 dalam Al-Qur'an Surat Al-Baqarah}

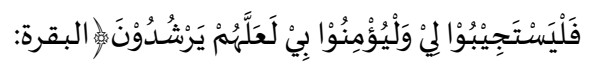

Hendaklah mereka itu meminta responku dan bendaklah mereka yakin kepada-Ku, agar mereka selalu mendapat petunjuk. QS. al-Baqarah: 186.

Pada ayat di atas, disyaratkan dua hal yang menjadi komposisi sebuah doa, yaitu: istijabah (فليستجيبوا لي) dan iman (وليؤمنوا بي).

1. Istijabah (فليستجيبوالي)

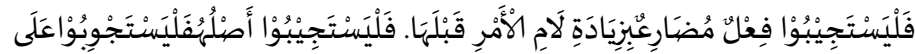

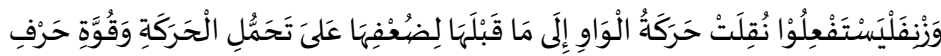

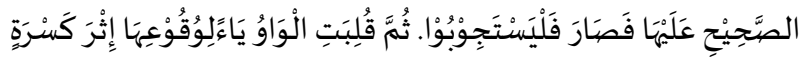

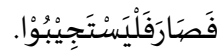

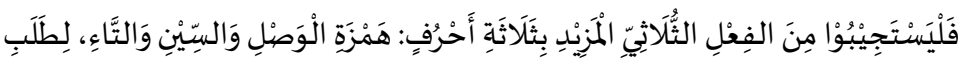

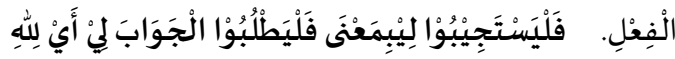

Secara bahasa istijabah berarti meminta respon. Sebagai unsur komposisi do'a, meminta respon dapat dilakukan dengan cara bekerja keras. Manusia harus

${ }^{19}$ Manupraba. 
bersungguh-sungguh dalam bekerja dan atau berusaha, untuk membuktikan keseriusan permohonannya kepada Tuhan.

Setiap manusia memiliki impian dan cita-cita. Agar dapat mencapainya, manusia mulai menggantungkan harapan dan permohonannya kepada Tuhan. Dari sini lah proses istijabah dimulai. Manusia harus bekerja keras, berani menghadapi berbagai rintangan, dan tidak mudah putus asa ketika tersandung kegagalan.

2. Iman (وليؤنوا بي)

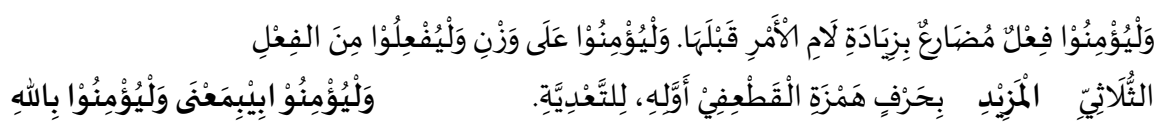

Secara bahasa iman berarti memiliki keyakinan. Sebagai unsur komposisi doa, memiliki keyakinan dapat dilakukan dengan cara mempercayakanapapun hasil dari kerja kerasnya kepada Yang Maha Berkehendak.

Sekeras apapun usaha yang dilakukan manusia, tetaplah Tuhan yang menentukan hasilnya. Keberhasilan ataupun kegagalan, sebenarnya keduanya adalah jalan yang ditunjukkan oleh Tuhan agar manusia tetapberada dekat dengan-Nya. Melalui keberhasilan, manusia diajari untuk bersyukur. Sedangkan melalui kegagalan manusia diajari untuk bersabar.

Malah, kadang keberhasilan itu diberikan untuk mengajari manusia cara bersabar, menahan diri dari kesombongan dan keangkuhan. Sedangkan kegagalan itu kadang diberikan untuk mengajari manusia cara bersyukur, merasa cukup dengan apa yang dimiliki atau dicapai.

Ketika kedua syarat di atas (istijabah) (usaha keras) dan iman (yakin) terpenuhi dengan baik, maka komposisi doa pun menjadi lengkap. Dengan itu, manusia berhak menikmati jaminan dari Tuhan, yaitu mereka akan selalu memperoleh petunjuk-Nya.

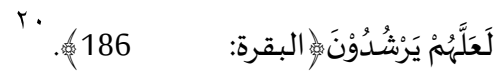

Agar mereka selalu mendapat petunjuk QS. Al-Baqarah: 186

Hal tersebut sejalan dengan konsep berdoa dalam perspektif psikologi. Berdoa merupakan aktivitas yang melibatkan peran psikis pelakunya secara mendalam dan dapat meningkatkan kecerdasan emosionalnya. Sehingga, dia akan cenderung memiliki daya untuk survive dalam memahami tujuan hidupnya. ${ }^{21}$

\footnotetext{
${ }^{20}$ Manupraba.

${ }^{21}$ Harmathilda H. Soleh, "Do'a dan Dzikir dalam Meningkatkan Kecerdasan Emosi," PSIKIS-Jurnal Psikologi Islami, 1, 2 (2016): 29-39, Hlm. 32.
} 
Adapun untuk rentang waktu antara permohonan dari hamba dengan respon dari Tuhan itu dinamis, disesuaikan dengan kebutuhan hamba yang telah diskenariokan oleh Tuhan. Ini digambarkan melalui potongan ayat,

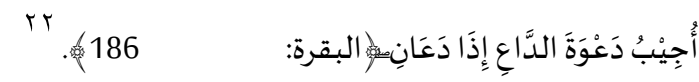

Aku merespon permohonan seorang pemohonjikadia memohon kepada-Ku QS. Al-Baqarah: 186.

Verba "Aku merespon" menggunakan fi'il mudhari" أُجِيْيَ, sedangkan "dia memohon" menggunakan fi'il madhi دَّا. Jika susunan potongan ayat tersebut dibalik, dari jawab-syarat menjadi syarat jawab, Apabila dia (seorang pemohon) memohon kepada-Ku, Aku merespon permohonannya, maka akan didapati, bahwa bagi seorang pemohon yang sudah memohon kepada Tuhan, Tuhan sesungguhnya sedang melangsungkan respon untuk permohonannya.

Dengan kata lain, sejak seorang hamba berdoa kepada Tuhan, sejak saat itu pula dia mulai direspon oleh Tuhan. Hanya, bagimana cara pandang hamba terhadap respon Tuhan lah yang kadang memberikan kesan bahwa Tuhan kadang menunda permohonan kita. Padahal, sesungguhnya Tuha sekali pun tidak pernah mengabaikan permohonan hamba yang memohon kepada-Nya. Jadi, pernyataan tentang kegagalan adalah keberbasilan yang tertunda harusnya diganti dengan kegagalan adalah jalan juang menuju keberhasilan.

\section{Penutup}

Setelah melakukan analisis morfologi pada ayat 186 dalam al-Qur'an Surat al-Baqarah, peneliti menemukan bahwa kata doa disebutkan sebanyak tiga kali dalam bentuk derivasi: da'watun (دعوة); mashdar = permohonan, ad-daa'i (دعال)); isim fa'il = pemohon, dan da'aa (دعا); fi'il madhi = memohon.

Peneliti juga menemukan dua hal yang menjadi komposisi doa, yaitu: istijabah (فليستجيبوالي) = kerja keras dan iman (وليؤمنوا بي) = yakin.Hanya akan disebut doa jika itu terdiri dari istijabah dan iman. Artinya, seseorang baru akan dikatakan berdoa ketika dia melakukan usaha keras dan yakin kepada kekuasaan Tuhan. Sejak seseorang mulai mengerjakan kedua hal tersebut, sejak itu pula dia mulai direspon oleh Tuhan. 


\section{Bibliografi}

Chaer, Abdul. Linguistik Umum. Jakarta: RinekaCipta, 2007.

Fajar, Dadang Ahmad. Epistimologi Doa. Bandung: NuansaCendekia, 2011.

Fathoni, Hanif. "Pembentukan Kata dalam Bahasa Arab (Sebuah Analisis Morfologis 'K-T-B').” Jurnal at-Ta'dib, 1, 8 (2013): 45-48.

Hakim, Awaludin. "Doa dalam Perspektif al-Qur'an Kajian Tafsir Ibnu Kathir dan Tafsir al-Azhar." Jurnal al-Fath, 1, 11 (2017): 45-70.

Irawati, Retno Purnama. Linguistik Umum. Jakarta: RinekaCipta, 2013.

Istiqomah, Himatul. "Konsep Manusia Sebagai Insan dalam Sebagian Ayat AlQur'an.” Prosiding Konasbara IV (2018): 439-45.

Keraf, Gorys. Linguistik Bandingan Historis. Jakarta: PT Gramedia Pustaka Utama, 1991.

Mahsun. Metode Penelitian Bahasa. Jakarta: Rajawali Press, 2014.

Manupraba, Wisnu. “TafsirQ.com.” Tafsir al-Quran Online (blog), 2019. https://tafsirq.com.

Mappiase, Arman. "Afiks Derivasional dan Infleksional Bahasa Sobey di Kabupaten Sarmi Provinsi, Papua." Metalingua, 1, 15 (2017): 13-24.

Ma'shum bin Ali. al-Amtsilah at-Tashrifiyah. Maktabah Syekh Salim bin Sa'ad Nabhan, 1965.

Moleong, Lexy J. Metode Penelitian Kualitatif. Bandung: Remaja Rosdaya, 2004.

Nur, Tajudin. "Infleksi dan Derivasi dalam Bahasa Arab: Analisis Morfologi." Metalingua, 2, 16 (2018): 273-83.

Ramlan, M. Ilmu Bahasa Indonesia, Morfologi. Suatu Tinjauan Deskriptif. Yogyakarta, 1978.

Rosi, Fauzi Fathur. "Dimensi I'jaz al-Qur'an pada Pengulangan Ayat dalam Surah Ar-Rahman (Telaah Terhadap Tafsir Fi Dhilal al-Qur'an Karya Sayyid Quthb)". Tesis, UIN SunanAmpel, 2018.

Setiawan, Ebta. "KBBI Online." Kamus Besar Bahasa Indonesia (KBBI) (blog), 2019. https://kbbi.web.id.

Soleh, Harmathilda H. "Do'a dan Dzikir dalam Meningkatkan Kecerdasan Emosi." PSIKIS-JumalPsikologiIslami, 1, 2 (2016): 29-39.

Solehudin. "Epistimologi Doa KH Asep Mukarram.” Syifa Al-Qulub, 1, 2 (2017): $12-25$.

Syaripudin, Undang. "Pembuatan Game Ilmu Shorof (Tashrief) Sebagai Media Pembelajaran Bahasa Arab.” Jurnal ISTEK, 1-2, 6 (2012): 125-36. 
260 | Arabiyatuna : Jurnal Bahasa Arab, Vol. 3, No. 2, 2019 